\title{
News and Announcements
}

\section{Aviation Human Factors Related Industry News ${ }^{1}$}

\section{Study Uncovers Some Factors That Might Affect the Amount and Quality of Airline Pilots' In-Flight Sleep}

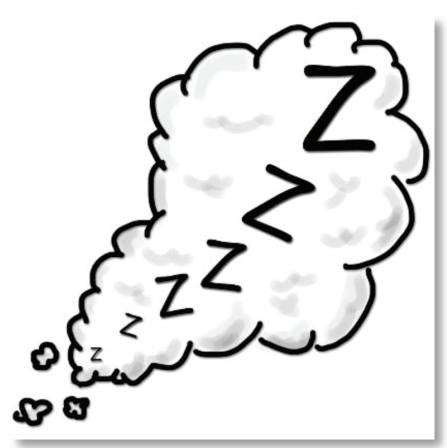

New research in PLoS One sheds light on how airline pilots use inflight sleep to manage fatigue on long-haul flights. The study indicates that many pilots try to prepare their body for sleep before the trip even begins. The new study examined qualitative feedback from pilots, which had been collected during previous studies on their sleep and performance. In particular, the previous studies surveyed pilots regarding their sleep at home, in-flight sleep, fatigue and performance on specific flight routes.

The surveys provided space for participants to comment at the end of the questionnaire, which is what the current study is based on.

"As I merged data from multiple studies into a larger database, I noticed that the pilots' comments had information in them that wasn't being captured in the scales and closed answer questions we were asking pilots to complete for our studies," explained study author Jennifer Zaslona, a research officer at the Sleep/Wake Research Centre at Massey University.

"We talk about shared responsibility for managing fatigue but we were focusing on what we could measure and forgetting to listen to the people being impacted by our recommendations. To me, it seemed that we were missing part of the picture."

After systematically coding comments from 123 airline pilots, the researchers found that several common themes emerged. For example, many pilots noted that the design and location of the crew rest facility could adversely affect in-flight sleep.
"On long range (> $8 \mathrm{hrs}$ ) and ultra-long range (> $16 \mathrm{hrs})$ flights, in-flight sleep is one of the main methods recommended to manage pilots' fatigue and sleepiness. This means that on long flights pilots are provided with crew rest facilities which can range from an economy class seat to a separate lie-flat bunk area depending on the flight," Zaslona told PsyPost.

"Pilots in our study made good use of their in-flight sleep opportunities (as recommended) and unsurprisingly they preferred the crew bunk area to the seat in the passenger cabin. However, they also highlighted ways in which the comfort of the crew bunk can be improved, for instance by reducing noise disturbances or providing softer mattresses." As one pilot said, sleeping in the crew bunk area was "like sleeping on a wellpadded carpet over hard floor."

Many pilots also said that they tried to prepare themselves before the flight, either by sleeping in on the day of their trip to get more rest before the flight or by increasing their time awake prior to their trip so they would have an easier time falling asleep in flight.

"Importantly, they indicated that their fatigue management on these flights actually starts before the flight with how they prepare for the flight. There were different strategies of flight preparation but pilots indicated that it is helpful for them to know ahead of time which rest breaks they will be allocated in flight so that they can better prepare for the flight," Zaslona said. The study - like all research includes some limitations.

"One of the main limitations of this study is that the questions from which we drew this data weren't designed to be the primary outcomes of the study, so the amount of information provided by each pilot is more limited than if we had conducted interviews or focus groups," Zaslona said.

"For example, the data doesn't address pilots' views on collaboration and communication with superiors and airlines in relation to fatigue risk management. It is also difficult to assess how representative of the general pilot population our sample is because the studies from which we drew our data were more of a snapshot of the operation during a specific period of time."

${ }^{1}$ Parts of this section are compiled from "Aviation Human Factors Industry News" and reproduced with permission of Roger Hughes. 
"There are still many questions to answer especially relating to flight preparation and rest break allocation. Owing to the variety in long haul flight operations it is unlikely that there would be a simple answer to these questions but perhaps we can start to identify different strategies that can be used in specific contexts," Zaslona explained.

"Traditionally, regulatory bodies have set hard limits on flight durations but with newer technologies aircraft can fly longer and further so there has been a shift towards using Fatigue Risk Management Systems (FRMSs)," she added.

"An FRMS provides an airline with more flexibility, allowing them to operate outside the prescribed limits, provided that they are monitoring and managing fatigue risk in their operations. But an FRMS also relies on all parties (regulators, airlines and pilots) doing their part to manage the risk of fatigue because fatigue is a whole of life issue, meaning fatigue is impacted by your work but also by what you do outside of work."

Retrieved from https://www.psypost.org/2019/08/study-uncoverssome-factors-that-might-affect-the-amount-and-quality-of-airlinepilots-in-flight-sleep-54222

Zaslona, J. L., O’Keeffe, K. M., Signal, T. L., \& Gander, P. H. (2018). Shared responsibility for managing fatigue: Hearing the pilots. PLoS One, 13(5), e0195530. https://doi.org/10.1371/journal. pone. 0195530

\section{Technology Soars in Advancing Critical Communication, Safety for Pilots and Passengers}

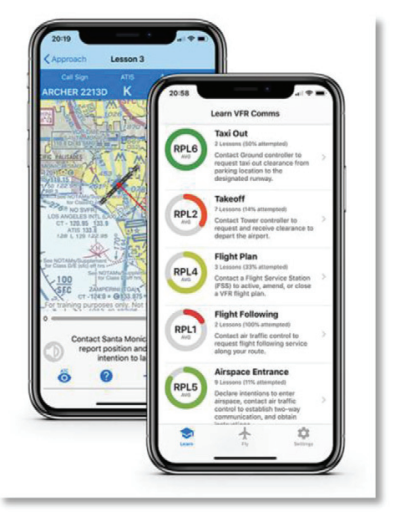

The Federal Aviation Administration has been putting an increased focus on English language proficiency for pilots as the agency looks to ensure safety for passengers through improved communication.

The move means increased attention for a technology called "Plane English," created by two Purdue University alumni that aims to help new pilots master radio communication skills and better interact with air traffic controllers.

Muharrem Mane, an alumnus from the School of Aeronautics and Astronautics, and Eren Hadimioglu, an alumnus from the School of Aviation and Transportation Technology, created and developed PlaneEnglish. The technology's simulator is now used in dozens of airports across the United States and was recently launched for iOS.
"PlaneEnglish is an aviation radio simulator to help new pilots acquire radio communication proficiency by developing advanced skills more in realistic environments," Mane said. "We have heard from users that they improve their radio communication skills more in one hour through our platform than they do in flying for a dozen hours."

The app-based tool also aims to help new pilots reach FAA and International Civil Aviation Organization standards for Aviation English language use, put in place to ensure safety in the sky.

PlaneEnglish is an aviation radio simulator to help new pilots acquire radio communication skills.

"We have been analyzing audio training files from the FAA and ICAO and using that data to establish our grading metrics to help users achieve the necessary communication skills to increase their radio proficiency and aviation safety," Mane said.

PlaneEnglish lessons guide users through simple and complicated interactions with air traffic control on every phase of flight. Each simulation includes visual clues (like altitude, distance from an airport and direction) to provide the pilot with the situational awareness necessary for communication.

Users are required to respond properly in specific situations, using the correct phraseology, speech rate and other factors. There can be as many as five or six exchanges back and forth with air traffic control. Then users are graded on those responses.

The work aligns with Purdue's Giant Leaps celebration, celebrating the university's global advancements in space exploration as part of Purdue's 150th anniversary. This is one of the four themes of the yearlong celebration's Ideas Festival, designed to showcase Purdue as an intellectual center solving real-world issues.

The creators of PlaneEnglish are working with the Purdue Research Foundation as they develop their technology.

\section{About Purdue Research Foundation}

The Purdue Research Foundation is a private, nonprofit foundation created to advance the mission of Purdue University. Established in 1930, the foundation accepts gifts; administers trusts; funds scholarships and grants; acquires property; protects Purdue's intellectual property; and promotes entrepreneurial activities on behalf of Purdue. The foundation manages the Purdue Foundry, Purdue Office of Technology Commercialization, Purdue Research Park and Purdue Technology Centers. The foundation received the 2016 Innovation and Economic Prosperity Universities Award for Innovation from the Association of Public and Land-grant Universities. For more information about funding and investment opportunities in startups 
based on a Purdue innovation, contact the Purdue Foundry at foundry@prf.org.

Retrieved from https://www.purdue.edu/newsroom/ releases/2019/Q3/technology-soars-in-advancing-criticalcommunication,-safety-for-pilots,-passengers.html

For more information, please contact Chris Adam (cladam@prf.org) or Muharrem Mane (muharrem@ planeenglish.net)

\section{How Autopilot Was Born a Century Ago}

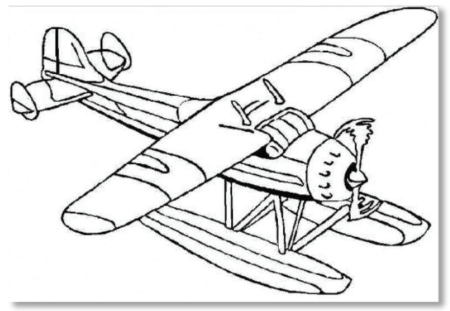

Just over 100 years ago in Paris two men flew in a biplane along the River Seine, lined with spectators. When one pilot lifted his hands in the air and the other walked out onto the wing it was the first public demonstration of autopilot.

In the plane that day were two men. French mechanic Emil Cachin and American aviation pioneer Lawrence Sperry. Sperry was the son of the famous inventor and entrepreneur Elmer A. Sperry, often referred to as the "father of modern navigation technology."

He created several companies during his lifetime, including an electric, mining machine and fuse wire company. But then he established the Sperry Gyroscope company, a business that grew to become a global technological powerhouse. Elmer's company turned the gyroscope, a children's toy, into usable technology to help tackle real-world problems.

Among his creations were a version of the gyrocompass, used by the U.S. Navy and adopted by many other countries during the first world war. Over this period, he also developed a gyro pilot system for ship's steering and built the first full gun battery fire control system. He also designed a gyro stabilizer, designed for ships, to reduce the roll caused by waves, particularly during rough conditions.

Lawrence Sperry's original aircraft gyroscopic autopilot was a smaller, lighter version of the gyro stabilizer based on the same principles.

"I mean they were fundamental to all flying. A lot of people made gyroscopes but Sperry was right at the beginning," says Graham Rood, a retired aviation engineer.

"For engineers and certainly people who can look back and understand history they were real giants of aviation and that's how they should be remembered." The Sperry corporation went on to develop other gyroscopic instruments such as the artificial horizon and the heading indicator which are still built into many of today's modern aircraft.

While gyroscopes were Elmer's and Laurence's most successful venture they continued to create a wide variety of equipment and machinery. In total, they held more than 400 patents for new inventions across several different industries. What later became the Sperry Corporation, before a series of corporate mergers, eventually became a part of the American global IT company Unisys.

Following the merger, some of its former divisions were sold off and have gone on to form parts of Honeywell, Lockheed Martin, United Technologies and finally Northrop Grumman. Last year, each company had revenues of more than $\$ 30$ billion.

Retrieved from https://www.cnbc.com/2019/07/19/ how-autopilot-was-born-a-century-ago1.html

\section{Carb Icing Leads to Forced Landing}

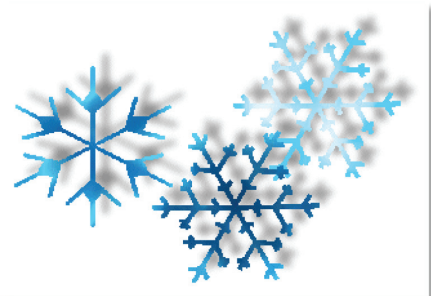

The airline transport pilot flew his experimental, amateurbuilt biplane on a cross-country flight with multiple legs and refueling stops. About 1 hour, 15 minutes into the flight and 15 miles from his destination, he initiated a descent from $3,500^{\prime}$ to $2,500^{\prime}$.

When he added power to level off, the Acro Sport II's engine began to run rough and experienced a partial loss of power. The pilot said he immediately applied carburetor heat, but observed no improvement in engine operation. The engine continued to lose power and "sputter."

During the subsequent forced landing near Loudonville, Ohio, the airplane touched down on unsuitable terrain at the edge of a soybean field, decelerated rapidly, and nosed over.

A post-accident examination of the wreckage revealed no pre-impact anomalies that would have precluded normal operation of the engine. Nearby weather was conducive to serious icing at descent power about the time of the engine power loss.

Although the pilot reported that he applied carburetor heat, it is likely that, at the time of application, the ice had already accumulated in the carburetor to the extent that the carburetor heat was insufficient to melt the ice and restore full engine power.

Probable cause: A partial loss of engine power due to carburetor icing.

This July 2017 accident report is provided by the National Transportation Safety Board. Published as an educational 
tool, it is intended to help pilots learn from the misfortunes of others.

Retrieved from https://www.ntsb.gov/_layouts/ntsb. aviation/brief.aspx?ev_id=20170801X70113\&key=1.

\section{AF447: Air France Sent Back to Court, Case Dismissed for Airbus}

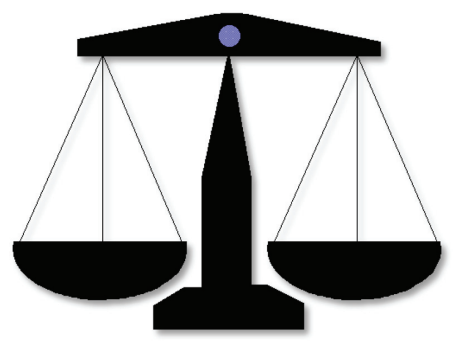

The Paris Public Prosecutor has requested Air France to face trial for manslaughter and negligence in the training of pilots, following the crash in 2009 of flight AF447 between Rio de Janeiro and Paris which killed 228 people. The Prosecutor also asked to dismiss a case against Airbus, whose A330-200 crashed in the middle of the Atlantic after an icing of the Pitot probes.

On June 1, 2009, an Air France A330, registered F-GZCP, carrying out flight 447 from Rio de Janeiro to Paris crashed at sea, killing all 228 people on board. The accident remains the worst Air France has ever suffered, and the deadliest involving an Airbus A330.

The final report of the French Bureau of Enquiry and Analysis for Civil Aviation Safety (BEA), released in 2012, pointed at icing of the Pitot probes and incorrect pilot reactions as the main causes of the crash. As for the criminal investigation, it was concluded on February 18, 2019. Since then, families have been awaiting a trial. On June 4, 2019, the SNPL, Air France's main pilot union, demanded everyone involved in the crash to be sent to court.

On July 12, 2019, the office of Paris Public Prosecutor required for Air France to be sent to court. It considers that the airline "committed negligence and imprudence" by not providing its pilots with sufficient information on the procedures to be followed, especially after several incidents of the same kind occurred during the preceding months. "This negligence and carelessness are certainly related to the accident, as the pilots, insufficiently informed, felt a strong surprise when the autopilot disconnected and could not have the appropriate reaction," says the office.

As for Airbus, it should not be prosecuted due to "an absence of sufficient evidence". This decision is contested by the "Association entraide et solidarité vol AF447", which represents around 360 family members of the victims. "For years, the builder Airbus has tirelessly tried to forget the obviousness and simplicity of the cause of the disaster: Pitot probes and automatisms," says the association, adding that no trial "can only comfort Airbus in a feeling of impunity harmful to the safety of all".

The SNPL also voiced its "incomprehension" of the decision. It claims that Airbus should also be tried, as it failed to recommend proper training to pilots. But the prosecutor dismissed the manufacturer's responsibility as the documentation of Airbus had been validated by the authorities. "To fully understand what it is, it is as if Boeing was relieved of all liability in the 737 MAX accidents on the grounds that the FAA had certified the aircraft," says the union.

While Air France said it was already preparing its defense, the investigating judges of the Paris court will now decide to follow or not the requisitions of the Public Prosecutor's office.

Retrieved with permission from https://www.aerotime. aero/clement.charpentreau/23726-af447-air-france-sentback-to-court-case-dismissed-for-airbus. Original published by Clément Charpentreau at www.aerotime.aero on July 22, 2019. 